Article

\title{
Insights into the Use of Social Comparison in Migrants' Transnational Social Positioning Strategies
}

\author{
Inka Stock \\ Faculty of Sociology, Bielefeld University, 33501 Bielefeld, Germany; E-Mail: inka.stock@uni-bielefeld.de
}

Submitted: 14 August 2020 | Accepted: 8 October 2020 | Published: 18 February 2021

\begin{abstract}
This article discusses the role of social comparisons in the processes through which migrants make sense of their own social position from a transnational perspective. Migrants are often involved in transnational forms of life which influence their forms of belonging, their economic strategies, their moral values and their political actions. There is also evidence to suggest that migrants use transnational frames of reference to evaluate their social positioning within their origin and host countries. In this article, we offer a methodological approach to the study of social positions in transnational spaces which aims to account for the interplay between the markers of objectively verifiable social positions and their subjective assessment by migrants. Concretely, we focus on social comparison as a mechanism for symbolic boundary-drawing processes, which help migrants to make sense of their (often differing) social positions within host and origin countries. Social comparisons help migrants to evaluate how they are seen and positioned by others and subsequently bring these assessments into line with their own social categories and evaluations of their social position in different places. These findings highlight the importance of social comparisons as a tool to investigate the interaction between social and spatial mobility.
\end{abstract}

\section{Keywords}

migrants; mobility; social comparison; transnational social position; social mobility

\section{Issue}

This article is part of the issue "Migration and Unequal Social Positions in a Transnational Perspective" edited by Thomas Faist (Bielefeld University, Germany).

(C) 2021 by the author; licensee Cogitatio (Lisbon, Portugal). This article is licensed under a Creative Commons Attribution 4.0 International License (CC BY).

\section{Introduction}

While mobility becomes more and more valued and accessible for certain groups of people, global securitisation policies and migration controls contribute to increasing restrictions on the mobility of others. For migration scholars, it has therefore become increasingly important to ask what kind of spatial mobility holds the promise of social mobility-and for whom.

One way to approach these complex and multifaceted questions of the relationship between social and spatial mobility is to focus on the influence of political, social and economic structures in both receiving and sending states on migrants' own perceptions of status mobility in host and origin countries. The advantage of this perspective is that it allows us to acknowledge the transnational dynamics in migrants' lives and how they shape social positions across national boundaries (Anthias, 2001, 2002; Nowicka, 2013; Rye, 2018; Weiss, 2005).

A better understanding of migrants' own views of their social status also offers insights into the mechanisms by which people are categorised by others and fit into social hierarchies that function beyond state levels. This is because subjective perceptions of social status are often reflections of the categorisations imposed on us by others (Dannenbeck, 2002; Jenkins, 1996). Thus, studying social status perceptions may help us better understand how structural and individual factors influence one another in the reshaping and reproduction of social hierarchies in transnational spaces. They may explain which type of migrants are more prone to perceive themselves as socially upwardly mobile and why and in which contexts. 
This article seeks to advance academic debates about which methodological and conceptual approaches would enable us to better investigate and understand how social inequalities across borders are experienced and made sense of by people themselves. It aims to contribute to this debate by focusing on the practices of social comparison. Social comparisons are understood as a tool people use to connect social and symbolic boundaries in their own processes of making sense of social positions. In line with Lamont and Molnár (2002, p. 3) we define social boundaries as objectified forms of social difference, manifested in unequal access to and unequal distribution of resources and social opportunities. Symbolic boundaries, on the other hand, are understood as tools which individuals use to come to agree upon definitions of reality. In this understanding, social boundaries are therefore both symbolic and real because boundary-drawing processes have the power to both reproduce and transform existing social boundaries between and within groups. In other words, here we look at social comparison as a mechanism used by migrants to situate themselves within objectifiable social and ethnic boundaries in a given society-which are mostly drawn upon by the majority population.

The article starts from the premise that the process of social comparison in itself is conditioned by social structures which become visible in different forms in local and international contexts, such as racialised, gendered or citizenship structures of inequality. In this vein, migrants may well reproduce invisible social structures of inequality when articulating their subjective assessment of their social position, or, alternatively, create new social boundaries between themselves and others through the enactment of specific symbolic boundaries which they establish during the process of comparing and distinguishing themselves from others. In this sense, processes of comparison are inherently part of localised processes of exclusion and inclusion on the basis of race, ethnicity, gender or citizenship that migrants are subjected to. In this article, the focus lies particularly on the role of social comparison as a social mechanism (Faist, 2019) employed by migrants to draw symbolic boundaries between themselves and others.

The article is based on data from 37 qualitative interviews with migrants in Germany who originated from a range of socio-economic backgrounds, working positions and countries of origin, and who had differentiated educational achievements. The interviews were part of the mixed-methods research project "Transnational Social Positions in the European Union" at Bielefeld University (for more details see the Supplementary File). In the first part of the article, we define and operationalise the concept of social comparison in the context of boundary theory. After this, the methodological design of the study and challenges in its application in practice are addressed. Here, the focus lies particularly on the benefits of qualitative approaches to reconstruct people's own frames of comparison. Challenges inherent to such interpretative approaches are also addressed; particularly those related to the classification and organisation of comparisons. The remainder of the article is dedicated to some preliminary findings in order to show how social comparisons can be used to explain the nexus between social and spatial mobility. In particular, the analysis shows that focusing on social comparison in migrants' narratives may be a good way to uncover how people make sense of ethnicised and gendered social and symbolic boundaries in transnational social spaces. Furthermore, the findings indicate that transnational social comparisons appear to serve people to portray themselves in more advantageous social positions than it might seem to outsiders.

\section{Transnational Social Positions, Boundary Theory and Social Comparison in Migration Research}

\subsection{Transnational Social Positions}

When talking about transnational social positions or social mobility in transnational spaces, we are drawing on the concepts of social status, originally developed by Pierre Bourdieu $(1984,1990)$ in his theory of cultural class struggle. Bourdieu recognised structural conditions such as people's relation to the means of production as determinant forces of class, but he also recognised cultural, symbolic and social components as important in reproducing class privilege. Migrant scholars have expanded Bourdieu's original theories in order to account for migrants' shifting social status dynamics from a transnational perspective (Nee \& Sanders, 2001; Nowicka, 2013; Weiss, 2005). In particular, specific emphasis has been placed on the role that different types of social, symbolic and cultural capital in the origin and destination countries may play for migrants' ability to obtain and maintain a certain social status in their home and host countries (Cederberg, 2017; Oliver \& O'Reilly, 2010; Rye, 2018; Zontini \& Reynolds, 2018). These authors suggest that migrants' evaluation of social status differ from Bourdieu's original and quite nationfocused understanding of social status, because in their subjective evaluation of social status migrants consider how symbolic, economic, cultural and social capital can be converted or adapted across national boundaries and within transnational social spaces.

By transnational social spaces, we refer here to the international webs of social, political and economic relationships between countries of origin and destination in which migrants are often embedded. Transnational social spaces emerge when pre-migratory ties and linkages are fostered by migration and congeal in economic, political and social patterns (Faist, 2000, p. 199). It has been ventured that the specific role that transnational frames of reference play in migrants' evaluation of their status mobility may be due to the fact that migrants often experience status paradoxes (Nieswand, 2011; Parreñas, 2000; Rye, 2018) when they change their geographical 
and social location through migration. In other words, they may experience particular challenges in becoming included in the new social group hierarchies they encounter in their host societies, while at the same time forming new and different connections to the social, cultural and economic fields in their country of origin after having migrated. This also suggests that migrants' social positioning processes may be based on a complicated interplay between both structural and individual factors which interact in transnational spaces (Anthias, 2001, 2002).

\subsection{Social Comparison and Its Link to Social Positioning Strategies and Boundary Theory}

In this article, it is argued that social comparison can be used as a tool to empirically document these dynamic processes of social positioning that migrants are engaged in. White $(2012$, p. 3) rightly observes that "social comparison is best treated as an interpretative heuristic, a way of making sense, in idealised form, of how others in turn make sense of the social world." Thus, methodologically, social comparison may be studied successfully through interpretative forms of enquiry as a way to make visible how people understand, transform and/or reproduce social hierarchies, thus shaping exclusionary and inclusionary group formation processes.

Only a few studies (Louie, 2006; Suárez-Orozco \& Suárez-Orozco, 1995) have used transnational frameworks to study social comparisons. Faist, Bilecen, Barglowski, and Sienkiewicz (2015) found that migrants' comparisons of different types of formal social protection offered by different nation states shape the exchange of informal social protection between migrants and their families and friends abroad. Not only did these comparisons reveal who received what kind of protection, but they also indicated a broader connection: social comparisons appeared to contribute to the perception of upward social mobility in terms of formal protection, income and career chances compared to migrants' situation in their region of origin. However, when migrants compared themselves with the standards of the destination countries, they perceived their social rank more towards the bottom of the social status scale, possibly because their educational and occupational qualifications from their home country were not (fully) recognised.

These different studies indicate that mobile people (and their immobile significant others) may develop transnational frames of reference for comparisons that pattern their self-positioning in transnational social spaces (Faist \& Bilecen, 2015, p. 290). There is initial evidence that cross-national comparisons frame the perceptions of social positions and concomitant experiences, such as relative (dis-)advantage, which can lead to situations of losing face, of conflict, and of frustration within migrants' families and beyond (Faist et al., 2015). However, we still do not know if all migrants engage in social comparisons in the same way and, if not, how this is related to social mobility dynamics and their geographical trajectories. How far can social comparison be understood as a social mechanism responsible for processes of making sense of inequality structures in transnational spaces? This is what we shall focus on in the subsequent parts of this article.

In this article, social comparison is understood in line with Festinger (1954) as a universal mechanism, which people use in every situation in which they need to position themselves and where no 'objective' scales/measures (such as weight, height or age) for comparison and consequent positioning are available. We know from social psychology that social comparisons can be used to mediate the link between fear and affiliation (Schachter, 1959), or in the process of constructing the self in relation to the social group one is referring to (Tajfel \& Turner, 1985). Buunk and Gibbons (2007), for example, have shown that social comparison is frequent when people are unsure about their own standing, or when they lack confidence or are in competition with others. At the same time, analysing comparisons is useful to learn about people's perceptions of social positions in general. Social identity theory has found, for example, that comparison allows people to evaluate their own group favourably to others through in-group/out-group comparison. Comparisons are also used by members of social groups to attempt to differentiate themselves from one another (Tajfel \& Turner, 1985). Migration is often a life-changing experience which involves a great deal of uncertainty and the need to orientate oneself towards new social norms and groups. Therefore, understanding the practices of social comparison is potentially fruitful to analyse how mobile persons make sense of their social positions in the different social environments of the places they migrate to.

While social psychology has mostly been concerned with comparison as a mechanism of boundary construction between groups and with the mechanisms of the permeability of symbolic and social boundaries, sociologists have paid attention to comparisons when looking at processes of collective identity (Dannenbeck, 2002; Jenkins, 1996). They focus on how internal (in-group) and external (out-group) definitions of identity are conditioned through changing ties of solidarity between group members. They find, for example, that group identity is always changing and ambivalent, and often conditioned through gender, social relations and social boundaries. These findings on group identity also suggest that the way in which migrants are perceived as 'Others' in a given society interacts with the way they perceive themselves as 'different.' This interactive process of the constitution of 'difference' impacts on the frames of reference migrants use to evaluate their own status mobility because it is difficult to evaluate one's status within a group if one perceives that one is excluded from it. Evaluations of status mobility are thus not only dependent on social and symbolic boundary-drawing process- 
es which emanate from migrants themselves, but also from the people they interact with, namely the origin and destination societies. By focusing on social comparison as a tool for symbolic boundary-making processes for in- and out-group comparisons, we may therefore be able to tease out the categories which are relevant for migrants to position themselves in different scales or hierarchies, and on national, transnational or local levels (White, 2012).

The above suggests that boundary theory plays an important role when assessing the transnational particularities in migrants' self-evaluations of their social positions in localised or nationalised social hierarchies (Anthias, 2002; Wimmer, 2008, 2013). Lamont and Molnár (2002, p. 168) have defined boundaries as "conceptual distinctions made by social actors to categorize objects, people, practices and even time and space" which are expressed through processes of evaluation and serve as a medium "through which people acquire status and monopolize resources." Cultural sociologists who work in this tradition (Lamont, 1992; Sachweh, 2013) have found that people's use of symbolic boundaries depends upon their social position. While upper-middleclass respondents tend to draw boundaries on economic and cultural criteria, lower-class respondents are more inclined to use moral boundaries to distinguish themselves from others. While boundary theory has been applied in migration research, most studies so far have focused on the boundaries drawn by the host society in relation to migrants or 'ethnic others' (Alba, 2005; Bail, 2008; Parzer \& Astleithner, 2017; Wimmer, 2013). This type of research has been important in shaping our understanding of how host societies draw symbolic boundaries to construct the migrant as 'the Other,' and through this process 'ethicise' other social boundaries. In this article, however, we are more interested in looking at the ways in which migrants draw boundaries between themselves and others in order to negotiate and evaluate their own social positions within a given society and how they transform and reproduce their social positions in transnational space.

\section{Methods for Studying Social Comparisons}

In order to analyse the diverse trajectories of mobility in their relation to individuals' social positions, and how mobile persons interpret their social position, there is a need for a research design that allows us to relate the symbolic boundary-making processes that migrants are subjectively engaged in to objectively existing social stratifying structures. In this respect, it is acknowledged that processes of migrants' sense-making regarding their social position are shaped by their social, symbolic and cultural resources and their 'habitus' (Bourdieu, 1990), and are best studied with qualitative methods that reveal patterns of meaning (White, 2012).

In social psychology research on social comparison, data is usually empirically generated through the use of semi-experimental, quantitative research methods. This means that frames of comparison as well as the social environment in which these comparisons occur are artificially constructed by the researcher (Wheeler \& Miyake, 1992). However, understanding how people construct frames of comparison and in which moments they are used is crucial for the study of boundary processes because the frames of comparison highlight the social dimensions of life in which people experience a need to draw lines and distinctions between people or objects in order to make sense of processes of exclusion and inclusion.

In the qualitative interviews, this problem was addressed by choosing topics of conversation and questions related to the definition and subjective experience of social hierarchies and social status. Furthermore, a variety of visual methods were used during the interview process (like photo-ranking exercises and life graphs) in order to facilitate respondents to engage in comparisons and establish relationships between abstract concepts (see Supplementary File). While a detailed description of these methods is beyond the scope of this article, it is important to signal that they enabled the respondents in the ensuing conversations to situate themselves within the social hierarchies they had themselves created. Crucial for the success of the interviewing method proved its loose structure which enabled respondents to use their own words and ways of explaining while at the same time allowing the researcher to collect stories of social trajectories which could later be grouped into different categories with recurring patterns of comparisons.

In order to facilitate the systematic coding and analysis of the great diversity of comparisons we found in the data, a conceptual model from White (2012), which schematises the many different dimensions of social comparisons that may exist, was adapted (see Table 1). To construct this grid, insights from social psychological literature were included, such as Merton (1968) and Runciman (1966) on reference groups for comparison, as well as Albert (1977) on the temporal dimensions of comparisons. According to this model, frames for social comparison can be differentiated along two main axes: on the first dimension, we differentiate the criteria for comparisons which determine what exactly people are comparing and why. Here we can distinguish between, for example, comparisons of economic, cultural or social resources, as well as comparisons of moral values. These comparison criteria are related to the types of symbolic boundaries that people are drawing (Lamont, Pendergrass, \& Pachucki, 2015). These comparison criteria map the economic, social or cultural capital that people recognise as being relevant for one's social position, as well as the symbolic capital they perceive as necessary for achieving or maintaining a certain social status.

We can distinguish here particularly between instances in which people referred to capabilities or skills and socio-economic resources when making com- 
Table 1. Two dimensions of comparisons.

\begin{tabular}{|c|c|c|}
\hline \multirow{2}{*}{$\begin{array}{l}\text { Criteria for comparison } \\
\text { (1st dimension) } \\
\text { Reference for comparison } \\
\text { (2nd dimension) }\end{array}$} & \multicolumn{2}{|c|}{$\begin{array}{l}\text { Capabilities, resources (socio-economic boundaries) } \\
\text { Values and tastes (moral boundaries) } \\
\text { Rules and regulations (social and cultural boundaries) }\end{array}$} \\
\hline & Subject of comparison & $\begin{array}{l}\text { I } \\
\text { We } \\
\text { He/She }\end{array}$ \\
\hline & Person or group of comparison & $\begin{array}{l}\text { Socially close (family, friend) } \\
\text { Not socially close } \\
\text { Imagined } \\
\text { Societal or symbolic (ethnic group, gender, age group, } \\
\text { migrants, etc.) }\end{array}$ \\
\hline & Value & $\begin{array}{l}\text { Normative } \\
\text { Relative }\end{array}$ \\
\hline & Time & $\begin{array}{l}\text { In the past-now } \\
\text { Now-future } \\
\text { Counterfactual }\end{array}$ \\
\hline
\end{tabular}

parisons (representing socio-economic boundaries), values and tastes (representing moral boundaries) and rules and regulations to which people considered they adhered, or were able to transgress in comparison with others (representing social and cultural boundaries). The second dimension of differentiation describes the form that the comparison takes. Here, we can distinguish the reference group that people are comparing themselves with, the timeline and the value (either normative or relative) given to their comparative efforts. The distinction between normative and relative values is the difference in comparisons of what 'should be' with what is, or of 'what was' with what is, respectively. It is also possible that they use fictive personalities or essentialised group notions for comparison, such as 'the Germans,' 'women,' 'children,' 'a Turkish migrant,' or 'a young foreign student,' etc. Others directly compare their own experience with the experience of people they know. The grid was used to construct thematic codes for each dimension and sub-dimension that was retrieved in the interview data. According to the types of comparison that were used subsequently by respondents, different forms of symbolic boundary-making processes could then be described and analysed through sequential and hermeneutic analytical coding procedures.

\section{Comparisons as a Way to Talk about Ethnicised and Gendered Social and Symbolic Boundaries}

When respondents were asked to rank and compare the social positions of people with different occupation, gender, ages or ethnic origins in countries of origin and settlement during the photo-eliciting exercise, they frequently engaged in comparisons of social status between abstract groups, such as 'civil servants,' 'old people,' or 'people in offices.' People particularly from middle income countries emphasised, for example, that employ- ment status (civil servant or private sector employee) more than occupation itself influenced social status differently in their home country and in Germany. Some would say, for example, that while employment in the public sector was probably less well paid in their origin country, it offered job security and access to networks which protected them from economic risks and unemployment in an otherwise volatile economic environment. In these people's eyes, this was crucial for maintaining a good social position in their origin country, but less important in Germany where the risk of unemployment and lacking social protection was less pronounced.

This indicates that respondents recognised globally operating structural inequalities such as occupation and pay as defining elements of social hierarchies, but that they evaluated their importance with reference to localised contexts. While many respondents valued the importance of different markers differently in origin and host country, they all ordered social positions according to the level of formal education, occupations, salaries and age-irrespective of the national context they were referring to (either Germany or their origin country). Gender and ethnic origin were also incorporated into the rankings of social positions but did not play a superior role in the ranking order of the photos. Thus, it appears that institutional cultural capital (as in formal education), economic capital (as in occupations, assets and financial security) and age are recognised as 'universal' markers of social status for the migrants we interviewed, since our respondents recognised their importance in all national contexts they were referring to during the interviews. Gender and ethnic origin, by contrast, appeared to be considered as rather dynamic status-determining variables. Concretely, in their narratives, respondents related both aspects to symbolic capital, in that both were thought to enhance or devalue other forms of capital in particular social fields, such as in the family or in com- 
munity relations. This may suggest that, for our respondents, the primary importance of occupation, education and economic capital for social positioning strategies is a product of the centrality of economic relations in capitalist societies (Meisenhelder, 2000, p. 92).

However, the fact that gender or ethnic origin were not explicitly named in the same way as education, occupation or age as status determining features is also very likely due to the fact that racialised and gendered differences are, together with class, part of interlocking social stratification processes which create social positions. How each individual occupies a social position within such interlocking structures of social hierarchies is described by the term intersectionality (Hill Collins, 1995, p. 492). Conveying the complicated interplay of these structures and the effects they have in people's lives requires carefully crafted methods. It is likely that in our case, the photo exercise in itself was not able to bring out in depth respondents' own experiences or feelings in relation to this intersectional powerplay. This is probably because the ranking exercise focused on photos which depicted people acting out different occupations. This may have triggered respondents to focus on occupational status as a marker of social standing during the ranking exercise rather than on other intersecting social status markers, such as the gender and ethnic origin of the person performing the tasks in the pictures.

While the photo exercise was not able to show if migrants perceive ethnicity or gender as objective social boundaries in the same ways as occupation or pay, the analysis of the comparisons people engaged in during the exercise did provide important clues about the ways in which they conceived of gender and ethnicity as status relevant. This was because through comparisons, respondents were constructing ethnicised and gendered reference groups for determining their social standing in relation to others.

Research has shown that people's concept of their own social standing is only in part shaped by the perception of material inequalities such as jobs, pay or working conditions. In addition, people tend to construct their own personal vantage point from which to view social status hierarchies and their place within them by sampling their social setting. It has been shown that in order to do so, people tend to draw mentally on reference groups in their family, among friends and coworkers. As these reference groups tend to be fairly homogeneous, people are thus able to position themselves in the middle of their mentally constructed social hierarchies of equals (Evans \& Kelley, 2004, p. 6). In our case, too, respondents' justifications to explain why they positioned themselves in certain ways within the social hierarchies they had created through the photo ranking exercise were based on a number of comparisons with different reference groups. The three reference groups below were those with which respondents most compared themselves and others in order to position themselves socially:
1. Other migrants from other countries of origin who live in Germany.

2. People who share the same country of origin.

3. Perceived 'ethnic' Germans.

In contrast to the above mentioned research with nonmobile people by Evans and Kelley (2004), the reference groups our respondents used were not necessarily homogeneous. Instead, the three reference groups constituted important in- and out-group references during the interviews and are all identified on the basis of 'ethnic' origin. This may indicate that ethnicised boundaries are recognised as important symbolic boundaries of social status in Germany-at least for the migrants whom we interviewed.

In fact, in the process of describing their own social position, our respondents often referred to social comparisons between ethnicised reference groups in order to convert ethnic social boundaries of exclusion into symbolic ones of inclusion, thus allowing them to enhance their own social status in the process of narration. This happened, for example, in direct comparisons between respondents and Germans, which were used to convey how the respondents attempted to mitigate the fact that their different cultural values impacted their ability to 'fit into' the German social hierarchies. In these instances, the comparisons with Germans reveal how respondents perceived the downgrading of their cultural and moral values by German society as unjust. The comparisons were thus a cognitive manifestation of an aversion to any situation that could result in downward mobility (Burleigh \& Meegan, 2013).

In the example below, an Iraqi woman explains why she considers early marriage an asset and ascribes it a high cultural value, despite knowing that this idea and the corresponding gender roles are no longer valued by mainstream German society because it conveys the idea of the dependent woman who is worth nothing socially without being married to a man. Through the comparison she uses in the interview, however, she is able to convert her own value system into one that is superior to the 'German' value system:

You rarely hear about marriages between Germans, or Europeans in general. It is mostly foreigners who marry....Germans don't recognise the positive sides of marriage for our daughters. Here, on the other side of the road there is a [German] family with many daughters. I think they have five children. Four are girls. And these girls, 18 or 20 years old, they carry babies around with them, without fathers. My daughter, by contrast, she married when she was 18 years old and she has decided to go to university and she does not want to have children just yet. So these [German] girls, they admire that a woman is worth so much, and that she could have such a big wedding and so many presents and a car and this and that. She has a different value and why? These girls, they are more beauti- 
ful than my daughter. But when a young man can have a woman without respecting any rules, without taking responsibilities through marriage, why not? Why get married if everything is possible? Even some foreigners have learned this from the Germans. That's the way it is. Unfortunately.

This example shows how comparisons are useful to understand the different moral and social symbolic boundary making processes between themselves and the host population that people engaged in. In addition, the analysis of the comparisons used during the photo ranking exercise show how ethnicised and gendered differences play out in people's perceptions of social positions, even though respondents did not perceive these aspects as being as directly determinant for social status hierarchies as education, occupation and age. In the remainder of the article, we will concentrate on these types of comparisons and relate them to migrants' socioeconomic characteristics.

\section{Social Comparison in Migrants' Narratives: Mechanisms to Convey Contradictory Social Positions in Transnational Spaces}

Despite the existence of the above-mentioned seemingly universal social markers for social status, respondents had difficulties in positioning themselves socially with reference solely to their educational qualifications, economic assets, or the type of paid work they were doing, in either the social hierarchies they had created for Germany or for their origin country. Instead, they often indicated that they saw themselves as neither included nor excluded fully in either their origin or host societies, which made it difficult for them to establish clearly what social position they occupied within their host and/or origin societies when we asked them to. One respondent solved the problem of not being able to position herself within the photo collage she had created by picking four different photos and saying: "This is me, all this together in one person. And I am somewhere here in the middle."

Following Festinger (1954), this may be a good example of migrants' feeling of cognitive dissonance, meaning the unease felt when people are unable to evaluate their abilities or achievements by use of a variety of objective standards. However, the reluctance to position themselves in the social hierarchies of both origin and host countries may also be related to differences in amounts of knowledge. According to social psychologists, people see themselves in a wide range of situations and roles. Therefore, self-knowledge is organised around multiple roles, activities and relationships. Thus, evidently, people vary in the number and diversity of selves that they believe they possess (Smith \& Mackie, 2007, p. 102). This is connected to the theory of self-complexity (Linville, 1985) which stipulates that people differ in the degree they perceive themselves to have diverse self- aspects. According to Linville, self-complexity can thus be measured and expressed with high or lower values. It may be that mobility influences people's measures of self-complexity positively because they are living in complex and transnational contexts which require them to consciously act out a diversity of 'selves' in different social contexts. Some of the respondents effectively explained their reluctance to position themselves due to their ambivalent position in both origin and host societies. They explained, for example, that they felt to a certain extent like a 'foreigner' in their country of origin and simultaneously thought that their social environment did not consider them to be a full member of the host society either. As a result, a great variety of respondents indicated that they did not feel themselves 'either here or there' and that this made it difficult for them to position themselves within the social hierarchies of each country.

The fact that the respondents did not fit into national social hierarchies of social status did not, however, mean that they were not able to position themselves socially at all. Instead, they appeared to combine different national frames of reference regarding symbolic capital in order to construct a transnational 'assemblage position,' which reordered the values of their acquired economic, social and cultural capitals in a subjectively experienced, transnational social hierarchy of social positions, which included the differently localised reference groups they perceived as relevant to them. In the remainder of the interviews, respondents used different types of social comparison to convey this ambivalent positioning to the interviewer, in order to make sense of their places in the social hierarchies of both host and origin countries. Whenever respondents evaluated their own social position in Germany, for example, they tended to engage in comparisons between themselves and other (often essentialised) migrant groups in Germany, or between themselves and the German host population. In these instances, however, Germans were usually considered as 'out-group.' One woman from the Philippines described how she experienced 'Germans' as opposed to 'foreigners' when she first arrived:

I found the Germans were so unfriendly, so unlikable...and.... when I was in the language school, I was always very happy that there were so many foreigners there....and we always said things like: "Oh, the Germans" [rolls her eyes]...and I thought, my God, it will be difficult here. It is all, I mean, it is all so different in my home country. Germans are disciplined, with a totally different culture. They are kind of civilised.

When respondents were evaluating their social position in their home country, by contrast, they often compared themselves with people in their country of origin who had similar professional or social backgrounds or with members of their family and other, socially close people. These were considered 'in-group.' These comparisons often occurred without the interviewer's inter- 
vention. We could see that these types of comparison were frequently used to define processes and criteria of inclusion and exclusion in origin and host societies. This squares well with social psychology literature which has found that comparisons are generally used by people to evaluate their own group favourably to others through in-group/out-group comparison (Tajfel \& Turner, 1985). Festinger (1954) found that a lack of objective measurements leads people to compare themselves with others on a more subjective and individual level. In these instances, people tend to compare themselves with people who are similar to them or with whom they compare as an in-group.

Comparisons with people from their home country, other migrants or the German host population also occurred in the context of conversations about the factors that respondents considered relevant for their social mobility. These comparisons generally focused on socially constructed, cultural, moral and economic markers of difference. They were therefore indicative of symbolic boundary-making processes that respondents were engaging in when positioning themselves over time and in transnational contexts. In this context, it is interesting that almost all respondents indicated that they considered themselves to have experienced upward social mobility in comparison to their situation in their origin country before migration. However, when we compared these subjective evaluations of their social mobility with the respondent's occupational and financial status before and after migration, we generally did not see great variation with their pre-migratory lives. The social mobility that migrants perceived was certainly more related to the fact that they perceived themselves to have accumulated symbolic capital in both their host and origin countries through the migratory experience. As mentioned above, the fact that migrants perceive themselves in the middle stratum of social hierarchies is in itself not surprising, because it squares with research that demonstrates that people in general appear to position themselves socially in the middle of society (Evans \& Kelley, 2004). However, what is interesting here is the justifications that our respondents gave for their assessments.

Respondents argued their views with reference to transnational frames of reference regarding social status mobility (Anthias, 2002). Frequently, they argued that even though they were not earning a lot of money in their current job in Germany, they considered that they had achieved other important social status markers, such as having a family and children, a house or good social contacts and friends-which they would not have been able to obtain if they had not migrated. Others argued that they considered their social status higher than in their country of origin because they had achieved more scope for choice to do what they wanted in life and generally perceived greater opportunities for their future. Others argued that their social status had not changed at all.
Thus, the interviews showed that to understand migrants' evaluations of social status, it is important to acknowledge its multiple dimensions, which are composed of both economic and financial aspects, but equally contain moral, social and cultural facets. In this sense, the migrants' self-positioning strategies mirrored the Bourdieusian idea of social status (Bourdieu, 1990) when comparing different dimensions of their social standing before and after migration. Interviewees weighted these different status indicators by comparing themselves with groups they felt they belonged to or else by comparing themselves with groups of people they wished to distinguish themselves from. In difference to non-mobile people, migrants appear to refer to reference groups for social comparisons that are located in different national contexts, thus creating transnational frames of references for comparisons of social status positions. The differences in the types of comparisons that people were using to distinguish national social hierarchies and their own position within them indicate that personal status evaluations may be shaped not only by subjective evaluations but also by how people are perceived by others and by those groups they most identify with (Tajfel \& Turner, 1985).

\section{Conclusion}

This article has shown how social comparison can be used as a tool to investigate migrants' subjective views on social status mobility through qualitative methods by conceptually linking the study of symbolic and social boundaries with practices of social comparison. The empirical data show that migrants-like non-migrantsexperience social status positions as composed of both subjective assessments of social difference and the societal norms and values related to what determines social difference and standing in any given society. In short, migrants appear to build their assessment of social position on how they feel included into social groups by others as well as by themselves. However, in contrast to non-mobile populations, migrants are often made aware that these two assessments do not necessarily overlap, particularly when one changes national contexts. In line with Bourdieu, it can be argued that this can be explained when one considers that what counts as symbolic capital, necessary for social standing in any society, is a process of negotiation which includes powerful and less powerful groups in a given social space. Migration reconfigures the composition of the social spaces into which people are incorporated and changes the rules and norms that define symbolic capital formation (Reed-Danahay, 2017).

This article has shown how migrants respond to this situation with strategies of self-positioning which compensate for perceived or potential status loss. People use social comparison to make sense of contradictory social positions in origin and host societies. By comparing themselves socially with others through transnational frames of reference, they transform social boundaries of exclu- 
sion into symbolic ones of inclusion, in an effort to thus enhance their own social status - at least in their own perception. This finding is in line with social psychology literature on social comparisons more generally, which has found that the mechanism of social comparison is used frequently by people in order to locate their group membership (Lockwood \& Kunda, 1997; Tajfel, 1982) or their position vis-à-vis others in a more positive light than it might appear to outsiders (Helgeson \& Mickelson, 1995).

The processes of migrants' subjective positioning strategies show that assessments of social position are not necessarily bounded by a social space framed by the nation state. While the state is recognised in migrants' narratives as an important structuring factor of social space, it is not the only or most important one. Social relations spanning across countries enable migrants to situate themselves in transnational spaces in which status hierarchies are reconfigured through cultural, social and economic forces that are not exclusively shaped by state forces.

\section{Acknowledgments}

I would like to thank the three anonymous reviewers for their helpful comments. Sincere thanks also to Thomas Faist, Ingrid Tucci, Joanna Fröhlich and Umut Erel for their constructive criticisms on earlier drafts of this article.

\section{Conflict of Interests}

The author declares no conflict of interests.

\section{Supplementary Material}

Supplementary material for this article is available online in the format provided by the author (unedited).

\section{References}

Alba, R. (2005). Bright vs. blurred boundaries: Secondgeneration assimilation and exclusion in France, Germany, and the United States. Ethnic and Racial Studies, 28(1), 20-49. https://doi.org/10.1080/ 0141987042000280003

Albert, S. (1977). Temporal comparison theory. Psychological Review, 84(6), 485-503.

Anthias, F. (2001). New hybridities, old concepts: The limit of 'culture.' Ethnic and Racial Studies, 24(4), 619-141.

Anthias, F. (2002). Where do I belong? Narrating collective identity and translocational positionality. Ethnicities, 2(4), 491-514.

Bail, C. A. (2008). The configuration of symbolic boundaries against immigrants in Europe. American Sociological Review, 73(1), 37-59. https://doi.org/ $10.1177 / 000312240807300103$

Bourdieu, P. (1984). Distinction: A social critique of the judgement of taste. London: Routledge.
Bourdieu, P. (1990). The logic of practice. Palo Alto, CA: Stanford University Press.

Burleigh, T. J., \& Meegan, D. V. (2013). Keeping up with the Joneses affects perceptions of distributive justice. Social Justice Research, 26(2), 120-131. https:// doi.org/10.1007/S11211-013-0181-3

Buunk, A. P., \& Gibbons, F. X. (2007). Social comparison: The end of a theory and the emergence of a field. Organizational Behaviour and Human Decision Processes, 102(1), 3-21.

Cederberg, M. (2017). Social class and international migration: Female migrants' narratives of social mobility and social status. Migration Studies, 1(8), 1-19. https://doi.org/10.1093/migration/mnw026

Dannenbeck, C. (2002). Selbst- und Fremdzuschreibungen als Aspekte kultureller Identitätsarbeit [Selfattributions and labeling processes as aspects of cultural identity formation]. Wiesbaden: VS Verlag für Sozialwissenschaften.

Evans, M. D. R., \& Kelley, J. (2004). Subjective social location: Data from 21 nations. International Journal of Public Opinion Research, 16(1), 3-38.

Faist, T. (2019). The transnationalized social question: Migration and the politics of social inequalities in the twenty-first century. Oxford: Oxford University Press.

Faist, T. (2000). The volume and dynamics of international migration and transnational social spaces. Oxford: Clarendon Press.

Faist, T., \& Bilecen, B. (2015). Social inequalities through the lens of social protection: Notes on the transnational social question. Population, Space and Place, 21(3), 282-293. https://doi.org/10.1002/psp.1879

Faist, T., Bilecen, B., Barglowski, K., \& Sienkiewicz, J. J. (2015). Transnational social protection: Migrants' strategies and patterns of inequalities. Population, Space and Place, 21(3), 193-202. https://doi.org/ 10.1002/psp.1903

Festinger, L. (1954). A theory of social comparison processes. Human Relations, 7(2), 117-140. https://doi. org/10.1177/001872675400700202

Helgeson, V., \& Mickelson, K. (1995). Motives for social comparison. Personality and Social Psychology Bulletin, 21(11), 1200-1209.

Hill Collins, P. (1995). Symposium: On West and Fenstermaker's Doing Difference. Gender and Society, 9 (4), 491-94

Jenkins, R. (1996). Social identity: Key ideas. London: Routledge.

Lamont, M. (1992). Money, morals, and manners: The culture of the French and the American upper-middle class. Chicago, IL: University of Chicago Press.

Lamont, M., \& Molnár, V. (2002). The study of boundaries in the social sciences. Annual Review of Sociology, 28(1), 167-195. https://doi.org/10.1146/ annurev.soc.28.110601.141107

Lamont, M., Pendergrass, S., \& Pachucki, M. (2015). Symbolic boundaries. In J. Wright (Ed.), International encyclopedia of the social \& behavioral sci- 
ences (2nd ed., Vol. 23, pp. 850-855). Amsterdam: Elsevier. https://doi.org/10.1016/B978-0-08097086-8.10416-7

Linville, P. (1985). Self-complexity and affective extremity: Don't put all of your eggs in one cognitive basket. Social Cognition, 3(1), 94-120.

Lockwood, P., \& Kunda, Z. (1997). Superstars and me: Predicting the impact of role models on the self. Journal of Personality and Social Psychology, 73(1), 91-103. https://doi.org/10.1037/0022-3514.73.1.91

Louie, V. (2006). Growing up ethnic in transnational worlds: Identities among second-generation Chinese and Dominicans. Identities, 13(3), 363-394. https:// doi.org/10.1080/10702890600838118

Meisenhelder, T. (2000). Toward a field theory of class, gender and race. Race, Gender and Class, 7(2), 76-95.

Merton, R. (1968). Social theory and social structure. New York, NY: Free Press.

Nee, V., \& Sanders, J. (2001). Understanding the diversity of immigrant incorporation: A forms-of-capital model. Ethnic and Racial Studies, 24(3), 386-411. https:// doi.org/10.1080/01419870020036710

Nieswand, B. (2011). Theorising transnational migration: The status paradox of migration. New York, NY: Routledge.

Nowicka, M. (2013). Successful earners and failing others: Transnational orientation as biographical resource in the context of labor migration. International Migration, 52(1), 74-86. https://doi.org/ 10.1111/imig.12144

Oliver, C., \& O'Reilly, K. (2010). A Bourdieusian analysis of class and migration: Habitus and the individualizing process. Sociology, 44(1), 49-66. https://doi.org/ $10.1177 / 0038038509351627$

Parreñas, R. S. (2000). Migrant Filipina domestic workers and the international division of reproductive labor. Gender and Society, 14(4), 560-580.

Parzer, M., \& Astleithner, F. (2017). More than just shopping: Ethnic majority consumers and cosmopolitanism in immigrant grocery shops. Journal of Ethnic and Migration Studies, 44(7), 1117-1135. https:// doi.org/10.1080/1369183X.2017.1358080

Reed-Danahay, D. (2017). Bourdieu and critical autoethnography: Implications for research, writing and teaching. International Journal of Multicultural Education, 19(1). http://dx.doi.org/10.18251/ ijme.v19i1.1368

Runciman, W. (1966). Relative deprivation and social justice: A study of attitudes to social inequality in twen- tieth century England. London: Routledge and Kegan Paul.

Rye, J. F. (2018). Transnational spaces of class: International migrants' multilocal, inconsistent and instable class positions. Current Sociology, 67(1), 27-46. https://doi.org/10.1177/0011392118793676

Sachweh, P. (2013). Symbolische Grenzziehungen und subjektorientierte Sozialstrukturanalyse: Eine empirische Untersuchung aus einer MixedMethods-Perspektive [Symbolic boundaries and the subject-oriented analysis of social stratification: An empirical study from a mixed-methods perspective]. Zeitschrift für Soziologie, 42(1), 7-27.

Schachter, S. (1959). The psychology of affiliation: Experimental studies of the sources of gregariousness. Palo Alto, CA: Stanford University Press.

Smith, E. R., \& Mackie, D. M. (2007). Social psychology (3rd ed.). Hove: Psychology Press.

Suárez-Orozco, C., \& Suárez-Orozco, M. M. (1995). Transformations: Immigration, family life, and achievement motivation among Latino adolescents. Palo Alto, CA: Stanford University Press.

Tajfel, G. (1982). Social psychology of intergroup relations. Annual Review of Psychology, 33, 1-39.

Tajfel, H., \& Turner, J. C. (1985). The social identity theory of intergroup behavior. In S. Worchel \& W. G. Austin (Eds.), Psychology of intergroup relations (2nd ed., pp. 7-24). Chicago, IL: Nelson Hall.

Weiss, A. (2005). The transnationalization of social inequality: Conceptualizing social positions on a world scale. Current Sociology, 53(4), 707-728. https://doi.org/10.1177/0011392105052722

Wheeler, L., \& Miyake, K. (1992). Social comparison in everyday life. Journal of personality and Social Psychology, 62(5), 760-773. https://doi.org/10.1037/ 0022-3514.62.5.760

White, J. P. (2012). Parallel lives: Social comparison across national boundaries (LEQS Paper No. 47). https://doi.org/10.2139/ssrn.1988633

Wimmer, A. (2008). The making and unmaking of ethnic boundaries: A multilevel process theory. American Journal of Sociology, 113(4), 970-1022. https:// doi.org/10.1086/522803

Wimmer, A. (2013). Ethnic boundary making: Institutions, power, networks. Oxford: Oxford University Press.

Zontini, E., \& Reynolds, T. (2018). Mapping the role of 'transnational family habitus' in the lives of young people and children. Global Networks, 18(3), 418-436. https://doi.org/10.1111/glob.12185

\section{About the Author}

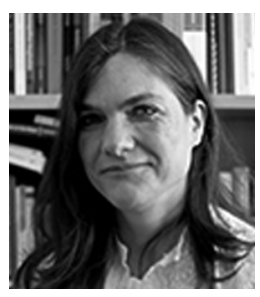

Inka Stock is a Post-Doctoral Researcher at the Centre on Migration, Citizenship and Development (COMCAD) at the Faculty of Sociology, Bielefeld University, Germany. She has a particular interest in the nexus between migration and inequality, migration and development and gender and migration. Her regional focus lies on migration in and from Africa. 